\title{
Correlates of autobiographical memory specificity: The role of depression, anxiety, and childhood trauma
}

Citation for published version (APA):

Wessel, I., Meeren, M., Peeters, F. P. M. L., Arntz, A. R., \& Merckelbach, H. L. G. J. (2001). Correlates of autobiographical memory specificity: The role of depression, anxiety, and childhood trauma. Behaviour Research and Therapy, 39(4), 409-421. https://doi.org/10.1016/S0005-7967(00)00011-5

Document status and date:

Published: 01/01/2001

DOI:

10.1016/S0005-7967(00)00011-5

Document Version:

Publisher's PDF, also known as Version of record

\section{Please check the document version of this publication:}

- A submitted manuscript is the version of the article upon submission and before peer-review. There can be important differences between the submitted version and the official published version of record.

People interested in the research are advised to contact the author for the final version of the publication, or visit the DOI to the publisher's website.

- The final author version and the galley proof are versions of the publication after peer review.

- The final published version features the final layout of the paper including the volume, issue and page numbers.

Link to publication

\footnotetext{
General rights rights.

- You may freely distribute the URL identifying the publication in the public portal. please follow below link for the End User Agreement:

www.umlib.nl/taverne-license

Take down policy

If you believe that this document breaches copyright please contact us at:

repository@maastrichtuniversity.nl

providing details and we will investigate your claim.
}

Copyright and moral rights for the publications made accessible in the public portal are retained by the authors and/or other copyright owners and it is a condition of accessing publications that users recognise and abide by the legal requirements associated with these

- Users may download and print one copy of any publication from the public portal for the purpose of private study or research.

- You may not further distribute the material or use it for any profit-making activity or commercial gain

If the publication is distributed under the terms of Article $25 \mathrm{fa}$ of the Dutch Copyright Act, indicated by the "Taverne" license above, 


\title{
BEHAVIOUR
}

RESEARCH AND

THERAPY

\section{Correlates of autobiographical memory specificity: the role of depression, anxiety and childhood trauma}

\author{
Ineke Wessel ${ }^{\mathrm{a}, *}$, Masja Meeren ${ }^{\mathrm{b}}$, Frenk Peeters ${ }^{\mathrm{c}}$, Arnoud Arntz ${ }^{\mathrm{b}}$, Harald \\ Merckelbach ${ }^{\text {a }}$ \\ a Department of Psychology, Maastricht University, PO Box 616, 6200 MD, Maastricht, Netherlands \\ ${ }^{\mathrm{b}}$ Department of Medical, Clinical and Experimental Psychology, Maastricht University, PO Box 616, 6200 MD, \\ Maastricht, Netherlands \\ ${ }^{c}$ Department of Psychiatry and Neuropsychiatry, Maastricht University, PO Box 616, 6200 MD, Maastricht, \\ Netherlands
}

Received 14 January 2000

\begin{abstract}
The present study examined the role of childhood trauma, major depressive disorder (MDD), and anxiety disorder $(\mathrm{AD})$ in overgeneral autobiographical memory. Ninety-three outpatients and 24 healthy controls completed a childhood trauma questionnaire and an autobiographical memory test (AMT). Results showed that MDD diagnosis rather than trauma history predicted AMT-performance. Memory specificity was not related to $\mathrm{AD}$ diagnosis, recovered $\mathrm{MDD}$, or self-rated depression severity. The present findings cast doubts on theories that emphasize the role of childhood trauma in overgeneral autobiographical memory. (C) 2001 Elsevier Science Ltd. All rights reserved.
\end{abstract}

Keywords: Autobiographical memory specificity; Mood disorders; Trauma

\section{Introduction}

Over the past few years, knowledge about autobiographical memory functioning in the emotional disorders has steadily accumulated (see for an overview Williams, 1996). One particularly interesting line of research has focused on the relative inability of some patients to retrieve

\footnotetext{
* Corresponding author. Tel.: +31-43-3881941; fax: +31-43-3884196.

E-mail address: i.wessel@psychology.unimaas.nl (I. Wessel).
} 
specific autobiographical memories even when they are explicitly instructed to do so. Instead, these patients respond to cue-words (e.g., 'happy') with so-called overgeneral memories, that is, memories reflecting several occurrences or a category of situations (e.g., "When I'm playing squash") rather than one specific event (e.g., "The day we left to go on holiday"; Williams \& Dritschel, 1988).

The phenomenon of overgeneral autobiographical memory was first described in a study that addressed the issue of why overdose patients display relatively long latencies to retrieve personal memories, especially in response to positive cue words (Williams \& Broadbent, 1986). Williams and Broadbent (1986) found that this latency effect was, at least in part, attributable to overdose patients producing more overgeneral memories than hospital controls. This study was instrumental in drawing researchers' attention to the more qualitative (i.e., specific vs overgeneral) aspects of autobiographical memory.

As overdose patients form a heterogeneous group, the question rises what characteristics of this group are associated with overgeneral autobiographical memory. A likely candidate is depression. Indeed, a recurrent finding is that patients with a diagnosis of current major depressive disorder display a tendency to produce overgeneral memories (Goddard, Dritschel \& Burton, 1996; Kuyken \& Dalgliesh, 1995; Moore, Watts \& Williams, 1988; Williams \& Scott, 1988). While the phenomenon has also been observed in anxiety disordered patients, there are indications that in these patients, overgeneral memories critically depend on co-morbid depression. For example, Burke and Mathews (1992, experiment 1) found that emotional memories of generalized anxiety disorder (GAD) patients were more overgeneral than such memories of control participants. However, the authors failed to find overgeneral memories in a second experiment. Moreover, the GAD patients reported significantly higher levels of depressed mood than the controls. Further evidence for the idea that overgeneral memories are linked to depression rather than to anxiety comes from a study of patients with obsessive-compulsive disorder (OCD; Wilhelm, McNally, Baer \& Florin, 1997). In that study, the most robust manifestations of overgeneral memories were found in those OCD patients who had co-morbid major depression.

The studies cited above could easily be interpreted as indicating that overgeneral recall of autobiographical events is nothing more than an epiphenomenon of a transient depressive state. However, there are good reasons to believe that a lack of specificity is not mood-dependent but rather reflects a stable trait (e.g., Williams, 1996). To begin with, a number of studies failed to find significant correlations between mood questionnaire scores and overgeneral recall (Kuyken \& Brewin, 1995; Merckelbach, Muris \& Horselenberg, 1996; Sidley, Whitaker, Calam \& Wells, 1997; Williams \& Dritschel, 1988). Furthermore, Williams and Dritschel (1988) found that recovered overdose patients were comparable to current overdose patients in terms of their autobiographical memory performance. Finally, a longitudinal study by Brittlebank and colleagues (Brittlebank, Scott, Williams \& Ferrier, 1993) showed that autobiographical memory performance at baseline, but not initial depression, predicted depression severity at 7-month follow-up. Taken together, these findings are consistent with the idea that overgeneral memories reflect a traitlike phenomenon.

There are some indications that overgeneral autobiographical recall may also be present in individuals who suffered from a psychological trauma. For example, studies on trauma-related anxiety disorders (i.e., posttraumatic stress disorder and acute stress disorder) demonstrate that overgeneral memory phenomena occur even after the contribution of depressed mood was statisti- 
cally partialled out (Harvey, Bryant \& Dang, 1998; McNally, Litz, Prassas, Shin \& Weathers, 1994; McNally, Lasko, Macklin \& Pitman, 1995). However, these studies also show that the presence of a trauma-related anxiety disorder rather than mere exposure to a traumatic event is associated with overgeneral memories. Still, there is some evidence that exposure to trauma in childhood may result in overgeneral autobiographical memory. Kuyken and Brewin (1995) noted that depressed women who were sexually abused in childhood had more difficulty in producing specific memories than depressed women without such a history. Thus, their finding suggests that overgeneral autobiographical recall may depend on childhood trauma rather than the presence of a trauma-related disorder per se. Following this line of reasoning Williams (1996) argued that traumatized children might adopt and persist in a general retrieval style in order to avoid memories of intensely aversive experiences.

To sum up, then, previous studies found little evidence for a link between anxiety disorder and a lack of memory specificity. However, this work was limited to patients with GAD (Burke \& Mathews, 1992) and OCD (Wilhelm et al., 1997). Still, stronger evidence exists for an association between overgeneral autobiographical recall and both pathological depression and a history of childhood trauma. Thus, the question rises whether both variables are independent and make a unique contribution to a lack of autobiographical memory specificity. To the extent that childhood trauma is the primary antecedent of overgeneral memories, such memories should occur in any patient with such a history, irrespective of diagnosis. Alternatively, if depression acts as the primary correlate of overgeneral memories, one would expect that such memories occur particularly frequently in patients with a (co-morbid) diagnosis of depression, whether or not they report traumatic childhood experiences. The present study sought to elucidate the precise contributions that pathological depression and childhood trauma make to a lack of autobiographical memory specificity. In addition, the role of anxiety disorders was further explored by including patients with various anxiety disorder diagnoses. Finally, to examine to what extent overgeneral memories reflect a trait-like phenomenon, the sample contained patients with remitted depression.

\section{Method}

\subsection{Participants}

\subsubsection{Patients}

Ninety-six outpatients from the anxiety disorders and the mood disorders clinics of the Ambulatory Mental Health Service (RIAGG) in Maastricht participated in the study. Three patients refused to fill in the CTQ (see below) and they were excluded from the analyses. This resulted in a final sample of 93 patients (51 women). Mean age of these patients was 36.6 years (range 20-58). About half of them (49.5\%) completed a medium or high level of education. ${ }^{1}$ Patients were diagnosed using the structured clinical interview for DSM-III-R (SCID, Spitzer \& Williams,

\footnotetext{
${ }^{1}$ Medium education level reflects an intermediate vocational qualification (MBO); high educational level refers to a college (HBO) or university degree.
} 
1986) or DSM-IV (First, Spitzer, Gibbon \& Williams, 1997; Groenestijn, Akkerhuis, Kupka, Schneider \& Nolen, 1999). They were included when they received a primary diagnosis of an anxiety disorder (AD) or major depressive disorder (MDD). To avoid confusion of a history of childhood trauma and trauma-related symptoms, patients with a diagnosis of posttraumatic stress disorder (PTSD) were excluded. This resulted in the following diagnostic groups: (1) AD without a history of MDD (AD: $n=31$ ); (2) AD and MDD in remission (AD/MDDIR: $n=20)$; (3) AD and current MDD (AD/MDD: $n=25$ ); and (4) current MDD (MDD: $n=17$ ). Anxiety disordered patients received a mean of $1.4 \mathrm{AD}$ diagnoses (range 1-4). Table 1 presents type of anxiety disorder diagnosis, as well as other demographic characteristics of each diagnostic group. As for use of psychotropic medication, a $\chi^{2}$ analysis showed that diagnostic categories differed in terms of the percentages of patients receiving medication, $\chi^{2}(3)=36.4, p<0.001$. Separate analyses showed that participants in the AD group received significantly less often medication than patients in both the AD/MDD, $\chi^{2}(1)=15.7, p<0.001$, and the MDD group, $\chi^{2}(1)=13.7, p<0.001$, with the AD/MDDIR group falling in between. Thus, AD/MDDIR patients tended to more often receive medication than AD patients did $(p=0.06)$, but less often than patients with a current major depression ( $p=0.05$ and $p=0.07$ for $\mathrm{AD} / \mathrm{MDD}$ and MDD groups, respectively).

\subsubsection{Controls}

Twenty-four healthy control participants (12 women) were recruited through a newspaper advertisement. They were administered the SCID through telephone to ensure that no diagnostic criteria were met. Control participants were paid for their participation.

The demographic characteristics of the patient groups and controls (see Table 1) were com-

Table 1

Demographic variables and anxiety disorder diagnosis in each diagnostic categorya

\begin{tabular}{lcllll}
\hline & AD $(n=31)$ & AD/MDDIR $(n=20)$ & AD/MDD $(n=25)$ & MDD $(n=17)$ & Control $(n=24)$ \\
\hline \% Women & 51.6 & 65 & 48 & 64.7 & 50 \\
Mean age $^{\text {b* }}$ & $32.0(9.5)$ & $37.5(8.5)$ & $38.6(8.9)$ & $40.9(8.8)$ & $35.1(10.4)$ \\
Mean education $^{\text {b }}$ & $7.5(2.1)$ & $7.1(2.1)$ & $6.9(2.2)$ & $6.7(2.4)$ & $7.2(2.3)$ \\
Medication $^{* *}$ & 12.9 & 35 & 64 & 64.7 & - \\
Type AD $^{c}$ & & & & & - \\
PD(AG) & 41.9 & 50 & 48 & - & - \\
SocPh & 41.9 & 40 & 36 & - & - \\
SpecPh & 25.8 & 10 & 28 & - & - \\
GAD & 9.7 & 25 & 12 & - & - \\
OCD & 9.7 & 15 & 12 & - & - \\
AD/NOS & 3.2 & - & - & & - \\
\hline
\end{tabular}

a $\mathrm{AD}=$ anxiety disorder; $\mathrm{MDDIR}=$ major depressive disorder in remission; $\mathrm{MDD}=$ major depressive disorder; $\mathrm{PD}(\mathrm{AG})=$ panic disorder, with or without agoraphobia; $\mathrm{SocPh}=$ social phobia; $\mathrm{SpecPh}=\mathrm{specific}$ phobia; $\mathrm{GAD}=$ generalised anxiety disorder; $\mathrm{OCD}=$ obsessive compulsive disorder; NOS=not otherwise specified. ${ }^{*} p<0.05 ;{ }^{* *} p<0.001$.

b Standard deviations are in parentheses.

c Percentage of patients with diagnosis within diagnostic category. Because multiple diagnoses could be given, the percentages add up to more than $100 \%$. 
pared. A one-way analysis of variance (ANOVA) revealed that there was a significant difference between groups in terms of age, $F(4,112)=3.26, p<0.05$. Post-hoc LSD tests showed that AD patients were significantly younger than AD/MDDIR, AD/MDD and MDD participants $(p s<$ 0.05), but did not differ from controls. Mean education and sex did not differ between groups.

\subsection{Assessment}

\subsubsection{Self-rating depression scale (SDS; Zung, 1965)}

The SDS was used to assess depressive symptom severity. The SDS contains 20 items that are scored on four-point Likert scales (range: 1=never to 4=always). The SDS was administered in the patient group only.

\subsubsection{Childhood trauma questionnaire (CTQ; Bernstein, 1995)}

The CTQ is a retrospective measure of various aspects of abuse and neglect during childhood. Items are scored on a 5-point scale (anchors: 1=never true and 5=very often true). Participants completed a Dutch translation of the 70-item original version (Bernstein et al., 1994). Analyses were restricted to the items of a more recent and shorter CTQ version (Bernstein, 1995; Bernstein, Ahluvalia, Pogge \& Handelsman, 1997). This version contains five subscales: emotional abuse (12 items; range 12-60), physical abuse (seven items; range 7-35), sexual abuse (seven items; range 7-35), emotional neglect (16 items; range 16-80), and physical neglect (eight items; range 8-40).

\subsubsection{Autobiographical memory test (AMT)}

The Dutch translation of the original AMT (Williams \& Broadbent, 1986) was used. Five negative and five positive cue-words were printed on separate sheets of paper in a booklet. Half of the patients saw the words in the following order: happy, clumsy, surprised, angry, interested, sorry, successful, hurt, safe, lonely. For the other half, the reverse order was used.

As in earlier studies (e.g., McNally et al., 1995; Wilhelm et al., 1997; Williams \& Dritschel, 1988) the specificity of the memories was judged. There were two raters. Agreement between raters was sufficient to good: Kappa's ranged between 0.62 (sorry) and 0.86 (safe). In addition, for the total number of specific memories agreement between judges was high (intra class correlation coefficient, ICC; $r=0.90$; Fleiss, 1986). Accordingly, AMT total scores were averaged over raters. For descriptive purposes, Table 2 shows mean AMT, SDS and CTQ scores for patients and controls.

\subsection{Procedure}

Participants were tested individually by a research assistant. After giving informed consent, they first completed the AMT. Participants were instructed that they were to write down a specific memory for each cue-word in the booklet. It was explained to them that a specific memory refers to a personally experienced event that happened at a particular time (within one day) and place. The first two items of the booklet were neutral practice items (car and tree). If necessary, more practice words were given (e.g., chair). It was not until the experimenter was confident that the 
Table 2

Means of autobiographical memory test (AMT), self-rating depression scale (SDS) and childhood trauma questionnaire (CTQ) per diagnostic category. Standard deviations are in parentheses ${ }^{\mathrm{a}}$

\begin{tabular}{|c|c|c|c|c|c|}
\hline & $\mathrm{AD}(n=31)$ & AD/MDDIR $(n=20)$ & $\mathrm{AD} / \mathrm{MDD}^{\mathrm{b}}(n=25)$ & $\operatorname{MDD}^{\mathrm{b}}(n=17)$ & Controls $(n=24)$ \\
\hline \multicolumn{6}{|l|}{ AMT } \\
\hline Total & $6.86(1.54)$ & $6.48(1.98)$ & $4.98(2.39)$ & $4.50(2.45)$ & $7.35(2.28)$ \\
\hline Positive & $3.50(0.99)$ & $3.25(1.14)$ & $2.44(1.13)$ & $2.29(1.2)$ & $3.85(1.19)$ \\
\hline Negative & $3.36(1.25)$ & $3.23(1.11)$ & $2.54(1.53)$ & $2.21(1.48)$ & $3.50(1.36)$ \\
\hline SDS & $45.10(7.93)$ & $50.90(9.07)$ & $59.88(6.34)$ & $58.94(8.31)$ & - \\
\hline \multicolumn{6}{|l|}{ CTQ } \\
\hline SA & $7.10(0.40)$ & $8.20(2.61)$ & $8.64(3.56)$ & $7.24(0.75)$ & 8.38 (3.10) \\
\hline PA & $8.21(2.11)$ & $9.15(4.25)$ & $10.16(4.46)$ & $10.35(4.11)$ & $8.75(2.25)$ \\
\hline PN & $9.84(2.41)$ & $10.15(3.52)$ & $10.72(2.65)$ & $10.35(3.62)$ & $10.71(2.85)$ \\
\hline EA & $19.03(6.14)$ & $24.2(10.39)$ & 27.35 (12.17) & $24.53(11.25)$ & $20.25(7.74)$ \\
\hline EN & $39.26(13.75)$ & $45.40(12.62)$ & $43.41(12.86)$ & $51.83(13.84)$ & 38.17 (12.9) \\
\hline
\end{tabular}

${ }^{\text {a }} \mathrm{SA}=$ =sexual abuse; $\mathrm{PA}=$ physical abuse; $\mathrm{PN}=$ physical neglect; $\mathrm{EA}=$ emotional abuse; $\mathrm{EN}=$ =motional neglect.

b SDS for one patient missing.

participant understood the instructions and had provided at least one specific memory in response to the practice words that the actual AMT started. Under each cue-word, participants wrote down a memory that the word reminded them of. Subsequently, they dated the memory. The test was largely self-paced. In case the participant did not turn to the next page after two minutes, (s)he was instructed to do so by the experimenter. Finally, participants completed the CTQ and SDS (patients only). Patients were assessed at the start of treatment.

\subsection{Statistical analyses}

Autobiographical memory performance was analyzed using hierarchical multiple regression techniques. Total number of specific memories was the dependent variable. In order to account for variance due to subject characteristics, demographic variables (i.e., age, sex, and educational level $)^{2}$ and use of psychoactive medication were entered on the first step. The second step involved a childhood trauma set containing the CTQ subscale scores of sexual abuse, physical abuse, physical neglect, emotional abuse, and emotional neglect. The third and final step involved a diagnostic set containing variables coded for the presence of MDD, an AD and remitted MDD (MDDIR). The rationale behind this particular hierarchy of predictors was that if childhood trauma underlies autobiographical memory problems, the diagnostic set of step three should not make a substantial contribution to explaining the variance in memory performance.

The contribution of depression symptom severity as indexed by the SDS was explored in a separate regression analysis that followed a similar hierarchy as the one outlined above, except

\footnotetext{
${ }^{2}$ Educational level was scored on an 11-point scale, ranging from 1=no education to 11=university degree.
} 
that SDS scores were entered as an independent variable before adding the diagnostic set. For all analyses, alpha was set at 0.05 .

Table 3 shows the first-order correlations between predictors. It can be seen from this table that these correlations ranged from $r=-0.34$ for MDD and MDDIR to $r=0.67$ for the CTQ-subscales of emotional abuse and physical abuse. Given these intercorrelations, multicollinearity was unlikely to pose a problem.

\section{Results}

\subsection{Predictors of memory specificity}

Table 4 shows the results of the hierarchical multiple regression analysis with the total number of specific memories as the dependent variable. The demographic set accounted for a large portion of the variance. This was primarily due to level of education, $t(112)=4.01, p<0.001$. Including the trauma set in the regression model did not make a significant contribution, $F$-change (5, $107)=0.99, p=0.43$. However, adding the diagnostic set resulted in a significant $11 \%$ increase in explained variance, $F$-change $(3,104)=6.36, p<0.01$. The presence of a current major depression appeared to be a strong predictor of autobiographical memory specificity, $\beta=-0.44, t(104)=-$ $4.21, p<0.001$. As expected, anxiety disorder diagnosis did not predict memory performance. However, the expectation that remitted depression predicts autobiographical memory performance was not confirmed.

Table 3

Intercorrelations among predictor variables $(n=117)^{\mathrm{a}}$

\begin{tabular}{lcccccccccccc}
\hline & Sex & Age & Educ & Med & SA & PA & PN & EA & EN & SDS $^{\text {b }}$ & MDD & MDDIR \\
\hline Age & $-0.19^{*}$ & & & & & & & & & & & \\
Educ & 0.07 & -0.14 & & & & & & & & & & \\
Med & 0.09 & $0.26^{*}$ & -0.05 & & & & & & & & & \\
SA & 0.14 & 0.06 & -0.04 & 0.13 & & & & & & & & \\
PA & -0.03 & $0.19^{*}$ & 0.00 & 0.15 & $0.21^{*}$ & & & & & & & \\
PN & -0.14 & $0.16^{*}$ & 0.04 & 0.05 & $0.35^{*}$ & $0.42^{*}$ & & & & & & \\
EA & 0.08 & $0.21^{*}$ & 0.11 & $0.31^{*}$ & $0.39^{*}$ & $0.67^{*}$ & $0.58^{*}$ & & & & & \\
EN & -0.12 & $0.33^{*}$ & $-0.16^{*}$ & 0.14 & $0.26^{*}$ & $0.20^{*}$ & $0.40^{*}$ & $0.40^{*}$ & & & & \\
SDS & -0.01 & $0.24^{*}$ & $-0.22^{*}$ & $0.35^{*}$ & 0.17 & $0.24^{*}$ & 0.05 & $0.25^{*}$ & $0.20^{*}$ & & & \\
MDD & 0.01 & $0.25^{*}$ & -0.12 & $0.51^{*}$ & 0.05 & $0.22^{*}$ & 0.06 & $0.26^{*}$ & $0.22^{*}$ & $0.60^{*}$ & & \\
MDDIR & 0.10 & 0.06 & -0.00 & 0.02 & 0.06 & -0.01 & -0.03 & 0.07 & -0.06 & -0.10 & $-0.34^{*}$ & \\
AD & -0.03 & -0.09 & 0.06 & 0.09 & -0.00 & -0.04 & -0.06 & 0.05 & 0.09 & $-0.29^{*}$ & -0.09 & 0.33 \\
\hline
\end{tabular}

a Educ=education; Med=medication; $\mathrm{SA}=$ sexual abuse; $\mathrm{PA}=$ physical abuse; $\mathrm{PN}=$ physical neglect; EA=emotional abuse; $\mathrm{EN}=$ emotional neglect; $\mathrm{MDD}=$ major depressive disorder; $\mathrm{AD}=$ anxiety disorder; $\mathrm{MDDIR}=\mathrm{MDD}$ in remission. ${ }^{*} p<0.05$.

b SDS scores are available for patient group only $(n=93)$. Due to missing data for two patients, final $n=91$. 
Table 4

Summary of hierarchical multiple regression analysis of number of specific memories $(n=117)^{\mathrm{a}}$

\begin{tabular}{|c|c|c|c|c|c|c|}
\hline Step & $\Delta R^{2}$ & $\mathrm{DF}$ & $F$-change & $B$ & SE & $\beta$ \\
\hline 1. & 0.23 & 4,112 & $8.27^{* * *}$ & & & \\
\hline Sex & & & & 0.63 & 0.40 & 0.13 \\
\hline Age & & & & -0.04 & 0.02 & -0.16 \\
\hline Educ & & & & 0.37 & 0.09 & $0.34^{* * *}$ \\
\hline Med & & & & -0.82 & 0.43 & -0.17 \\
\hline 2. & 0.03 & 5,107 & 0.99 & & & \\
\hline Sex & & & & 0.66 & 0.42 & 0.14 \\
\hline Age & & & & -0.04 & 0.02 & -0.15 \\
\hline Educ & & & & 0.33 & 0.10 & $0.30^{* *}$ \\
\hline Med & & & & -0.89 & 0.46 & -0.18 \\
\hline $\mathrm{SA}$ & & & & -0.02 & 0.09 & -0.02 \\
\hline PA & & & & -0.07 & 0.08 & -0.10 \\
\hline PN & & & & 0.14 & 0.09 & 0.17 \\
\hline EA & & & & 0.03 & 0.03 & 0.12 \\
\hline EN & & & & -0.02 & 0.02 & -0.12 \\
\hline 3. & 0.11 & 3,104 & $6.36^{* *}$ & & & \\
\hline Sex & & & & 0.67 & 0.04 & 0.14 \\
\hline Age & & & & -0.03 & 0.02 & -0.12 \\
\hline Educ & & & & 0.30 & 0.09 & $0.27^{* *}$ \\
\hline Med & & & & 0.09 & 0.48 & 0.02 \\
\hline $\mathrm{SA}$ & & & & -0.04 & 0.08 & -0.05 \\
\hline PA & & & & -0.04 & 0.07 & -0.06 \\
\hline $\mathrm{PN}$ & & & & 0.10 & 0.08 & 0.12 \\
\hline EA & & & & 0.04 & 0.03 & 0.16 \\
\hline $\mathrm{EN}$ & & & & -0.01 & 0.02 & -0.06 \\
\hline MDD & & & & -2.14 & 0.51 & $-0.44^{* * *}$ \\
\hline MDDIR & & & & -0.48 & 0.58 & -0.08 \\
\hline $\mathrm{AD}$ & & & & -0.24 & 0.41 & -0.05 \\
\hline
\end{tabular}

a Educ=education; Med=medication; $\mathrm{CTQ}=$ childhood trauma questionnaire; $\mathrm{SA}=$ sexual abuse; $\mathrm{PA}=\mathrm{physical}$ abuse; $\mathrm{PN}=$ physical neglect; $\mathrm{EA}=$ emotional abuse; $\mathrm{EN}=$ emotional neglect; $\mathrm{MDD}=$ major depressive disorder; $\mathrm{MDDIR}=\mathrm{major}$ depressive disorder in remission; $\mathrm{AD}=$ anxiety disorder. Coding for sex was $0=$ male, $1=$ female. Coding for Med; MDD; MDDIR; and AD was $0=$ absent, $1=$ present. ${ }^{* *} p<0.01 ;{ }^{* * *} p<0.001$.

Although childhood trauma did not predict autobiographical memory specificity, it is possible that trauma and memory are indirectly related. That is, perhaps the effects of childhood trauma on memory become apparent only when a MDD is also present. This was explored as follows. First, the MDD variable and the scores on each CTQ subscale were transformed into $z$-scores. Next, five variables were computed, each reflecting the interaction between standardized MDD scores and one of the standardized CTQ subscale scores (i.e., sexual abuse, physical abuse, physical neglect, emotional abuse, and emotional neglect). In a subsequent hierarchical multiple regression analysis, the first step consisted of entering the demographic variables set. The second step added the standardized MDD and CTQ subscale scores. This rendered a significant $14 \%$ 
increase in explained variance, $F$-change $(6,106)=3.90, p<0.01$. The third and final step entered the five interaction variables. This did not significantly increase explained variance, $\Delta R^{2}=0.05$, $F$-change $(5,101)=1.86, p=0.11$. Thus, a regression model including the interaction between childhood trauma and MDD did not more adequately predict memory specificity than a model that did not account for such an interaction.

\subsection{Cue-word valence}

Previous research (Williams \& Broadbent, 1986; Williams \& Dritschel, 1988; Williams \& Scott, 1988) noted that relative to negative cue-words, positive cues elicited less specific memories in current patients than in healthy controls. Interestingly, one study (Williams \& Dritschel, 1988) found a different pattern in recovered patients. In that study, recovered patients retrieved less specific memories only with negative but not positive cues compared to healthy controls. Accordingly, we examined whether current and remitted depression are linked to autobiographical memory specificity when cue-word valence is taken into account. A valence index was calculated by subtracting the number of specific memories to negative cue words from the number of specific memories to positive cues. Thus, a positive sign of this index reflects more specific memories to positive than to negative cues, whereas a negative sign indicates the opposite pattern.

The valence index was subjected to a hierarchical multiple regression analysis. The results showed that the demographic set accounted for a significant portion of the variance, $R^{2}=0.08$, $F(4,112)=2.54, p<0.05$. Within this set, education significantly predicted the valence index, $\beta=-0.19, t(112)=-2.06, p<0.05$, implying that more specific memories to negative than to positive cues were produced when educational level was higher. Neither childhood trauma, nor diagnosis significantly contributed to explained variance, $\Delta R^{2}=0.05, F$-change $(5,107)=1.15$, $p=0.34$, and $\Delta R^{2}=0.007, F$-change $(3,104)=0.28, p=0.85$, for the CTQ-subscales and diagnostic set, respectively. Thus, current and remitted depression were not associated with different response patterns to positive and negative cues.

\subsection{Contribution of depression severity}

In order to investigate to what extent depression severity predicts autobiographical memory specificity, an additional hierarchical multiple regression analysis was performed. In this analysis, SDS scores were entered in the third step, that is, after the demographic and trauma sets, but before the diagnostic set of variables. The rationale for doing so was as follows. If poor AMTperformance is the result of disturbed mood, diagnosis should not add to explained variance after depression severity is entered. Results of this analysis showed that SDS added $2 \%$ to explained variance of the model already containing demographic and trauma variables. This contribution was not significant, $F$-change $(1,80)=2.24, p=0.14$. The diagnostic set still made a significant contribution to explained variance, $\Delta R^{2}=0.09, F$-change $(3,77)=4.04, p<0.05$. Within this set, the presence of MDD was the only significant predictor, $\beta=-0.34, t(77)=-2.14, p<0.05$. Thus, clinical diagnosis rather than self-reported depression severity predicted autobiographical memory specificity. 


\section{Discussion}

The present study investigated to what extent depression and childhood trauma are implicated in overgeneral autobiographical memory. The results show that a clinical diagnosis of current major depression rather than self-reported childhood trauma predicts decreased autobiographical memory specificity. These findings are well in line with previous reports of relatively poor autobiographical memory performance in clinically depressed patients (Brittlebank et al., 1993; Goddard et al., 1996; Kuyken \& Brewin, 1995; Kuyken \& Dalgliesh, 1995; Moore et al., 1988; Williams \& Scott, 1988). However, there was no evidence to support the idea that currently depressed patients' memory is especially poor in response to positive cue-words (Williams \& Broadbent, 1986; Williams \& Dritschel, 1988; Williams \& Scott, 1988). Note, though, that a number of other studies (e.g., Goddard et al., 1996; Kuyken \& Dalgliesh, 1995; Moore et al., 1988) also failed to find an interaction between valence and diagnosis. Thus, it appears that such an interaction reflects an unstable phenomenon at best. Furthermore, we found that an anxiety disorder diagnosis is not associated with autobiographical memory specificity in an important way. This underscores the idea that whenever such a link is found, its source may well be comorbid depression (e.g., Wilhelm et al., 1997).

The clear association with MDD diagnosis raises the suspicion that a lack of autobiographical memory specificity is an epiphenomenon of a mood disturbance. Indeed, the absence of an association with remitted depression casts doubts on the idea that an overgeneral autobiographical memory reflects a stable trait that is independent of current depression. Meanwhile, a clinical diagnosis of MDD was a better predictor of autobiographical memory performance than self-reported depression severity. Thus, in light of the present findings neither an explanation involving full state-dependency, nor an interpretation in terms of a stable depressive trait seems to be justified. There are two issues that should be noted in this respect. First, our finding that self-reported depression severity does not predict autobiographical memory specificity is reminiscent of previous failures to detect an association between self-reported depression and overgeneral recall (Kuyken \& Brewin, 1995; Phillips \& Williams, 1997; Williams, Williams \& Ghadiali, 1998). The observation that poor autobiographical memory is intimately associated with depressive episodes, but not with scores on self-rated depression suggests that there are other and probably more subtle aspects of MDD that are responsible for overgenerality than merely the disturbed mood tapped by most depression inventories. Second, the lack of association between autobiographical memory specificity and remitted depression may have to do with characteristics of the sample under study. Note that patients with a remitted MDD also had a current anxiety disorder diagnosis. Perhaps these patients differ from remitted patients with no current disorder. If so, including patients with remitted depression only would have provided a more adequate test of the state-trait issue.

The present results do not support the idea that childhood trauma is an important antecedent of overgeneral memories. In contrast, Kuyken and Brewin (1995) found that depressed women who were sexually abused in childhood displayed more overgeneral memories than depressed women without such a history. There are a number of potential sources for the disparity between their study and ours. To begin with, it may be that group differences other than abuse history (e.g., more severe depression, more suicide attempts, etc. in the abused group) were responsible for the results reported by Kuyken and Brewin. On the other hand, trauma reports in our parti- 
cipants were relatively mild and infrequent. Closer inspection of the CTQ scores reveals that these predominantly fell in the minimal to moderate range (Bernstein, 1995). Thus, it remains possible that levels of trauma in the present studies varied insufficiently to detect an influence on autobiographical memory performance.

The present findings are difficult to reconcile with Williams' (1996) account of the origins of overgeneral memories. This author suggests that when young children are traumatized, normal autobiographical memory development is halted. By this view, traumatized children would never fully develop the skill of specific retrieval. Instead, they would continue to rely on an overgeneral retrieval style that characterizes early developmental stages. Yet, at the very least, the present findings warrant the conclusion that childhood trauma is not the only pathway to an overgeneral autobiographical memory. Thus, the explanatory power of theoretical accounts that emphasize the role of childhood trauma in the development of overgeneral memories seem to be of limited value.

What, then, is the mechanism underlying the connection between a lack of autobiographical memory specificity and a clinical diagnosis of MDD? One interesting clue is provided by the work of Brewin and colleagues (e.g., Brewin, Reynolds \& Tata, 1999; Reynolds \& Brewin, 1999). For example, Reynolds and Brewin (1999) found that the occurrence of intrusive autobiographical memories of negative life-events is a common feature of depression. In that particular respect, depression closely resembles PTSD, in which intrusive memory is a hallmark symptom. It is conceivable that intrusive memories and overgenerality are closely linked. Perhaps the price paid for the enhanced probability of recalling a certain autobiographical event is a decreased accessibility of all other material, resulting in a poor overall autobiographical memory. While this account would reconcile the results of studies showing overgeneral memories in PTSD (e.g., Harvey et al., 1998; McNally et al., 1994; McNally et al., 1995) and in depression, it should be empirically evaluated.

Another explanation for the link between MDD and lack of autobiographical memory specificity may lie in the motivational and/or concentration deficits displayed by clinically depressed people. Although it has been shown that cognitive sluggishness (e.g., Williams \& Broadbent, 1986; Williams \& Scott, 1988) is unlikely to be responsible for a lack of specificity, more subtle tests of motivation or concentration are uncommon in overgeneral memory research. Thus, to explore this possibility, such tests should be employed in future studies.

Apart from the theoretical implications of the current findings, two more issues deserve attention. The first issue is of a methodological nature. The present results show that educational level predicts memory performance. Thus, the higher a participant's education, the more specific memories (s)he produced. This may be due to the written format of the AMT that we used in our study. However, a link between autobiographical memory specificity and intelligence scores has also been reported in a study employing an oral form of the AMT (Williams et al., 1998). Interestingly, a negative link between IQ and PTSD has also been reported (Macklin et al., 1998; McNally \& Shin, 1995). Taken together, it seems advisable for future studies on autobiographical memory and/or trauma to control for individual differences in education or intelligence. The second issue worthy of note pertains to the practical relevance of the finding that diagnosis accounted for $11 \%$ of the variance in memory specificity. In statistical terms, this percentage reflects a medium effect size (Cohen \& Cohen, 1983). That is a rather encouraging result for research in the social sciences. Note further that this $11 \%$ reflects unique variance, that is, variance over and above the variance explained by individual differences variables (i.e., sex, age, education, 
medication) and CTQ scores. As for clinical significance, the present results indicate that depressed patients with relatively low levels of education are prone to show autobiographical memory difficulties (see also Table 2 for a comparison between groups). For such patients, therapeutic techniques that focus on becoming more specific may be especially beneficial.

In summary, the present results clearly show that a diagnosis of depression, rather than an anxiety disorder diagnosis predicts autobiographical memory specificity. Moreover, clinical depression was more important in predicting autobiographical memory performance than selfreported childhood trauma. As for this latter variable, however, our participants displayed relatively low levels of traumatization. Therefore, more severely traumatized patient samples should be studied to examine whether (childhood) trauma makes an extra contribution to the phenomenon of overgeneral autobiographical memory. It may well be the case that in patients diagnosed with depression and/or PTSD, the occurrence of intrusive memories rather than a history of trauma per se, acts as the primary determinant of overgenerality. Given the indications that overgenerality may predict the course of psychopathology (Brittlebank et al., 1993; Harvey et al., 1998; but see Brewin et al., 1999), parametric studies on the precise link between intrusive and overgeneral memory are clearly needed.

\section{Acknowledgements}

The Netherlands Organization for Scientific research (NWO) is gratefully acknowledged for funding this project. This research was conducted while Dr Wessel was supported by a grant of the Foundation for Behavioural and Educational Sciences of this organisation (575-29-001) awarded to Dr Merckelbach. We wish to thank Miranda Vermeeren, Madelon Sijsenaars, Jolanda Kouwenberg, Caroline Appels, and Han Keijsers at the RIAGG Maastricht for their invaluable help in various aspects of the organization of the project. We are grateful to Reinout Wiers for providing statistical advice and for critically commenting on an earlier version of the manuscript.

\section{References}

Bernstein, D. P. (1995). Manual for the childhood trauma questionnaire (CTQ). New York: Mont Sinai School of Medicine.

Bernstein, D. P., Ahluvalia, T., Pogge, D., \& Handelsman, L. (1997). Validity of the childhood trauma questionnaire in an adolescent psychiatric population. Journal of the American Academy of Child and Adolescent Psychiatry, 36, 340-348.

Bernstein, D. P., Fink, L., Handelsman, L., Foote, J., Lovejoy, M., \& Wenzel, K. et al. (1994). Initial reliability and validity of a new retrospective measure of child abuse and neglect. American Journal of Psychiatry, $151,1132-1136$.

Brewin, C. R., Reynolds, M., \& Tata, P. (1999). Autobiographical memory processes and the course of depression. Journal of Abnormal Psychology, 108, 511-517.

Brittlebank, A. D., Scott, J., Williams, J. M. G., \& Ferrier, I. N. (1993). Autobiographical memory in depression: State or trait marker? British Journal of Psychiatry, 162, 118-121.

Burke, M., \& Mathews, A. (1992). Autobiographical memory and clinical anxiety. Cognition and Emotion, 6, $23-35$.

Cohen, J., \& Cohen, P. (1983). Applied multiple regression/correlation analysis for the behavioral sciences. (2nd ed.). Hillsdale, NJ: Lawrence Erlbaum Associates. 
First, M. B., Spitzer, R. L., Gibbon, M., \& Williams, J. B. W. (1997). Structured clinical interview for DSM-IV axis I disorders. New York

Fleiss, J. L. (1986). The design and analysis of clinical experiments. New York: Wiley.

Goddard, L., Dritschel, B., \& Burton, A. (1996). Role of autobiographical memory in social problem solving and depression. Journal of Abnormal Psychology, 105, 609-616.

Groenestijn, M. A. C. V., Akkerhuis, G. W., Kupka, R. W., Schneider, N., \& Nolen, W. A. (1999). Gestructureerd Klinisch Interview voor de vaststelling van DSM-IV As I Stoornissen. (Structured clinical interview for DSM-IV axis I disorders). Lisse: Swets \& Zeitlinger B.V.

Harvey, A. G., Bryant, R. A., \& Dang, S. T. (1998). Autobiographical memory in Acute Stress Disorder. Journal of Consulting and Clinical Psychology, 66, 500-506.

Kuyken, W., \& Brewin, C. R. (1995). Autobiographical memory functioning in depression and reports of early abuse. Journal of Abnormal Psychology, 104, 585-591.

Kuyken, W., \& Dalgliesh, T. (1995). Autobiographical memory and depression. British Journal of Clinical Psychology, 34, 89-92.

Macklin, M. L., Metzger, L. J., Litz, B. T., McNally, R. J., Lasko, N. B., Orr, S. P., \& Pitman, R. K. (1998). Lower precombat intelligence is a risk factor for posttraumatic stress disorder. Journal of Consulting and Clinical Psychology, 66, 323-326.

McNally, R. J., Lasko, N. B., Macklin, M. L., \& Pitman, R. K. (1995). Autobiographical memory disturbance in combat-related Posttraumatic Stress Disorder. Behaviour Research and Therapy, 33, 629-630.

McNally, R. J., Litz, B. T., Prassas, A., Shin, L. M., \& Weathers, F. W. (1994). Emotional priming of autobiographical memory in Post-traumatic Stress Disorder. Cognition and Emotion, 8, 351-367.

McNally, R. J., \& Shin, L. M. (1995). Association of intelligence with severity of posttraumatic stress disorder symptoms in Vietnam combat veterans. American Journal of Psychiatry, 152, 936-938.

Merckelbach, H., Muris, P., \& Horselenberg, R. (1996). Correlates of overgeneral memories in normal subjects. Behavioural and Cognitive Psychotherapy, 24, 109-115.

Moore, R. G., Watts, F. N., \& Williams, J. M. G. (1988). The specificity of personal memories in depression. British Journal of Clinical Psychology, 27, 275-276.

Phillips, S., \& Williams, J. M. G. (1997). Cognitive impairment, depression and the specificity of autobiographical memory in the elderly. British Journal of Clinical Psychology, 36, 341-347.

Reynolds, M., \& Brewin, C. R. (1999). Intrusive memories in depression and posttraumatic stress disorder. Behaviour Research and Therapy, 37, 201-215.

Sidley, G. L., Whitaker, K., Calam, R. M., \& Wells, A. (1997). The relationship between problem-solving and autobiographical memory in parasuicide patients. Behavioural and Cognitive Psychotherapy, 25, 195-202.

Spitzer, R. L., \& Williams, J. B. W. (1986). Structured clinical interview for DSM-III-R (SCID). New York: New York State Psychiatric Institute, Biometrics Research.

Wilhelm, S., McNally, R. J., Baer, L., \& Florin, I. (1997). Autobiographical memory in Obsessive-Compulsive Disorder. British Journal of Clinical Psychology, 36, 21-31.

Williams, H. W., Williams, J. M. G., \& Ghadiali, E. J. (1998). Autobiographical memory in traumatic brain injury: Neuropsychological and mood predictors of recall. Neuropsychological Rehabilitation, 8, 43-60.

Williams, J. M. G. (1996). Depression and the specificity of autobiographical memory. In D. Rubin, Remembering our past: studies in autobiographical memory (pp. 271-296). Cambridge: Cambridge University Press.

Williams, J. M. G., \& Broadbent, K. (1986). Autobiographical memory in suicide attempters. Journal of Abnormal Psychology, 95, 144-149.

Williams, J. M. G., \& Dritschel, B. H. (1988). Emotional disturbance and specificity of autobiographical memory. Cognition and Emotion, 2, 221-234.

Williams, J. M. G., \& Scott, J. (1988). Autobiographical memory in depression. Psychological Medicine, 18, 689-695.

Zung, W. W. K. (1965). A self-rating depression scale. Archives of General Psychiatry, 12, 63-70. 